\title{
Correlation Between Immunohistochemical Biomarkers Expression and Prognosis of Ovarian Carcinomas in Tunisian Patients
}

\author{
Lobna Ayadia, d, Salma Chaabouni ${ }^{\mathrm{a}}$, Abdelmajid Khabir ${ }^{\mathrm{a}}$, Habib Amouri ${ }^{\mathrm{b}}$, Saloua Makni ${ }^{\mathrm{a}}$, \\ Mohamed Guermazi $^{\mathrm{b}}$, Mounir Frikha ${ }^{\mathrm{c}}$, Tahya Sellami Boudawara ${ }^{\mathrm{a}}$
}

\begin{abstract}
Background: Ovarian cancer is the leading cause of death from gynaecological malignancies. Newer biological prognostic factors and predictors of response to therapy are needed. Our study was designed to evaluate the expression of p53, Bcl-2, Estrogen receptor (ER) and Progesterone receptor (PR) in ovarian carcinoma and to compare it with other prognostic parameters such as age, FIGO stage, size of residual tumor, histological type and grade.
\end{abstract}

Methods: This is a retrospective study conducted in the department of pathology at Sfax University Hospital. Confirmed 57 cases of ovarian carcinoma were reviewed in the period between January 1995 and December 2006. We used immunohistochemistry to evaluate the expression of p53, Bcl-2, ER and PR receptors and ChiSquare and Student test to correlate immunohistochemical findings with some prognostic parameters of ovarian carcinoma.

Results: The percentage of expression of p53, Bcl-2, ER and PR was $73.7 ; 47.4 ; 35.1$ and $33.3 \%$ respectively. p53 overexpression correlated with an advanced FIGO stage $(p=0.026)$ and presence of ascitis $\left(\mathrm{p}<10^{-4}\right)$. The expression of PR was associated with an early stage (FIGO I and II), a non serous histologic type and a low tumour grade ( $\mathrm{p}=0.045 ; 0,010$ and 0,036 respectively). No correlation was found between Bcl-2 and ER and prognostic parameters. Survival analysis revealed that Bcl-2 status, FIGO stage, presence

\footnotetext{
Manuscript accepted for publication June 21，2010

${ }^{a}$ Department of Pathology, Habib Bourguiba University Hospital, Sfax, Tunisia

${ }^{b}$ Department of Gynecology, Hédi Chaker University Hospital, Sfax, Tunisia

${ }^{\mathrm{c}}$ Department of Oncology, Habib Bourguiba University Hospital, Sfax, Tunisia

${ }^{\mathrm{d}}$ Corresponding Author, Department of Pathology, Habib Bourguiba University Hospital, El Ain Road Km 0,5, Sfax 3029, Tunisia.

Email: ayadilobna@yahoo.fr
}

doi:10.4021/wjon2010.06.213w of ascites, peritoneal cytology, and residual disease were significant predictive factors of survival.

Conclusions: p53 expression correlates with a worse prognosis in epithelial ovarian cancer, whereas $\mathrm{Bcl}-2$ expression is related to a better outcome. For hormonal status, expression of PR is found to be an independent indicator of favourable prognosis. These results should be supported by more and larger studies.

Keywords: Ovarian carcinoma; p53; Bcl-2; Estrogen receptor; Progesterone receptor

\section{Introduction}

Epithelial ovarian carcinoma is worldwide the sixth most common female cancer [1]. This malignancy carries the highest mortality among all gynaecological cancers $[2,3]$. According to data from the Cancer Registry of Tunisia, ovarian carcinoma is the second gynaecological cancer with an incidence of 2.9/100000 inhabitants [4]. Identification of new biological prognostic markers would be of great importance to select patients with a possibly favourable or poor clinical outcome and might help to improve treatment planning [5].

Regulators of apoptosis, especially p53 and Bcl-2, and steroid hormone receptors, estrogen and progesterone, have been studied as potential prognostic factors of epithelial ovarian cancer.

P53 is a tumor suppressor gene located on the short arm of chromosome 17. Mutation of p53 is believed to result in uncontrolled cell proliferation [6]. Mutant p53 protein may be identified by immunohistochemical methods, related to the longer time required for the destruction of the mutant protein compared to the wild type [7].

The Bcl-2 gene, a member of the Bcl-2 family inhibits apoptosis and has been shown to exert antiapoptotic activity in ovarian carcinoma cells responding to chemotherapy [8].

Steroid hormones are thought to play an important role in the process of carcinogenesis in ovarian carcinoma. Estrogen may contribute to initiation and/or promotion of ovarian carcinogenesis. It is thus logical to speculate that the over- 
expression of ER should be associated with a poor prognosis [9]. On the other hand, progesterone may offer protection against ovarian carcinoma development.

The purposes of the present study were to study the immunohistochemical profile of p53, Bcl-2 and steroid hormone receptors in a series of 57 ovarian carcinomas, and to investigate their association with clinicopathological prognostic indicators.

\section{Patients and Methods}

\section{Patients and specimens}

In this study, we conducted a retrospective analysis of 69 epithelial ovarian cancers collected in the Sfax University Hospital between January 1995 and December 2006. Our study concerned a sample size of 57 because these were the only cases for which we had complete information about the patient and the tumor. Also, these were the only cases whose paraffin blocks had enough tissue to allow extra sections for our study and eventually for future examination. Borderline tumors were not included in this study.

In fact, epithelial ovarian cancer samples were studied after informed consent and IRB approval from the 57 patients. The patients' age ranged from 29 to 77 years (mean age $=54$ years). A total of $31(54.4 \%)$ patients were 55 years old or less and $26(45.6 \%)$ were older than 55 years. The FIGO 1988 classification was used in the database. Twenty (35.1\%) patients were in early FIGO stage (I/II) and 37 (64.9 $\%$ ) in later stage (III/IV). The histological type was determined on tissue sections according to World Health Organization criteria. The microscopic grading of Shimizu and Silverberg [10] was used: 15 cases were grade I, 19 cases grade II and 23 cases grade III.

The standard surgical procedure was: total abdominal hysterectomy, bilateral salpingo-oophorectomy, omentectomy, appendicectomy, multiple peritoneal biopsies and peritoneal washings with cytology. All patients received initial cytoreductive surgery which was complete or optimal in 31 cases $(54.4 \%)$ and suboptimal in 26 (45.6\%).

Patients were treated according to a standardized adjuvant chemotherapy protocol (Cisplatin: $50 \mathrm{mg} / \mathrm{m}^{2}$ and $\mathrm{Cy}-$ clophosphamide: $500 \mathrm{mg} / \mathrm{m}^{2}$ in combination in six courses given every three weeks. To assess response, reports from first surgery and second look laparotomy were reviewed and all tumor measurements were compared. Complete pathologic response was defined as the disappearance of all tumor at second-look laparotomy, with all biopsy specimens and peritoneal washings negative for tumor cells. Microscopic residual disease was defined as the disappearance of all macroscopic tumor lesions but the presence of tumor cells in one or more biopsy specimens or peritoneal washings. Partial response was defined as a $50 \%$ or more decrease in size of all bidimensionally measured tumor lesions. Stable disease was either a decrease in size of less than $50 \%$ or an increase in size of less than $25 \%$ of one or more measured tumor lesions. Progressive disease was defined as either a $25 \%$ or more increase in the size of one or more clinically measured lesions or the appearance of new disease manifestations or a $25 \%$ increase in size of one or more tumor lesions at secondlook laparotomy. All patients were followed up until death or August 2008. Follow-up information was collected from the medical records, and no patients were lost of follow-up. The median follow-up time for patients still alive was 31 months (range: 0-151 months). A detailed description of patient characteristics is given in Table 1 .

\section{Pathological diagnosis}

All surgical tissue specimens were fixed in 10\% formaldehyde, embedded in paraffin, sectioned and stained with hematoxylin/eosin. According to the WHO classification [11], histology revealed serous carcinomas in 24 (42.1\%), endometrioid carcinomas in $23(40.3 \%)$, mucinous carcinomas in $3(5.3 \%)$ and other histological types in 7 cases $(12.3 \%)$ (Table 2).

\section{Immunohistochemical staining}

Immunostaining for $\mathrm{p} 53, \mathrm{Bcl}-2, \mathrm{ER}$ and $\mathrm{PR}$ was performed for all specimens. Four micrometer sections attached on silanized slides were de-waxed in xylene, rehydrated in graded ethanol and covered with $10 \mathrm{mM}$ citrate buffer ( $\mathrm{pH}$ 6). They were then incubated for $30 \mathrm{~min}$ with primary monoclonal antibodies against p53 (DAKO, clone DO-7; 1:50), Bcl-2 (DAKO, clone 124; 1:100), ER (DAKO, clone 1D5; 1:25) and PR (DAKO, clone PgR636; 1:50), followed by incubation with biotin-labeled secondary antibodies. The streptavidin-peroxidase complex was visualized using di-aminobenzidine as a chromogenic substrate.

All slides were reviewed by the senior author with the supervision of one of the co-authors (AK) without knowledge of the clinical outcome. As positive controls, previously established positive cases of human tumors for p53, Bcl-2, ER and PR were used. For p53, ER and PR, only nuclear staining of the tumor cells was considered a positive expression. Bcl-2 immunostaining was typically cytoplasmic.

A semi-quantitative immunoreactive score was used to record results. The score is obtained by the product of intensity of immunostaining (none $=0$; weak $=1$; moderate $=2$; strong $=3$ ) and the percentage of positive tumor cells (none $=0 ; 1-25 \%=1 ; 26-50 \%=2 ; 51-75 \%=3 ;>75 \%=4)$.

\section{Statistical analysis}

Statistical analysis was used to evaluate correlations between expression of p53, Bcl-2, ER and PR and clinicopathologi- 
Table 1. Clinicopathological data $(n=57)$

\begin{tabular}{|c|c|c|}
\hline & $N$ & $\%$ \\
\hline \multicolumn{3}{|l|}{ Age } \\
\hline$\leq 55$ years & 31 & 54.4 \\
\hline$>55$ years & 26 & 45.6 \\
\hline \multicolumn{3}{|l|}{ FIGO Stage } \\
\hline $\mathrm{I} / \mathrm{II}$ & 20 & 35.1 \\
\hline III/IV & 37 & 64.9 \\
\hline \multicolumn{3}{|l|}{ Ascites } \\
\hline$<100 \mathrm{ml}$ & 23 & 65.2 \\
\hline$>100 \mathrm{ml}$ & 34 & 79.2 \\
\hline \multicolumn{3}{|l|}{ Cytology } \\
\hline Negative & 28 & 71.4 \\
\hline Positive & 29 & 75.9 \\
\hline \multicolumn{3}{|l|}{ Residual disease } \\
\hline None/Optimal & 31 & 54.4 \\
\hline Suboptimal & 26 & 45.6 \\
\hline \multicolumn{3}{|l|}{ Histologic type } \\
\hline Serous & 24 & 42.1 \\
\hline Non serous & 33 & 57.9 \\
\hline \multicolumn{3}{|l|}{ Tumor grade } \\
\hline $\mathrm{I} / \mathrm{II}$ & 34 & 59.6 \\
\hline p53 ${ }^{\text {III }}$ & 23 & 40.4 \\
\hline Negative & 15 & 26.3 \\
\hline Positive & 42 & 73.7 \\
\hline \multicolumn{3}{|l|}{ Bcl-2 } \\
\hline Negative & 30 & 52.6 \\
\hline \multicolumn{3}{|l|}{ ER Positive } \\
\hline Negative & 37 & 64.9 \\
\hline \multicolumn{3}{|l|}{ PR Positive } \\
\hline Negative & 38 & 66.7 \\
\hline Positive & 19 & 33.3 \\
\hline \multicolumn{3}{|l|}{ Surgery } \\
\hline Optimal & 31 & 54.4 \\
\hline Suboptimal & 26 & 45.6 \\
\hline \multicolumn{3}{|l|}{ Systemic chemotherapy } \\
\hline Adjuvant & 45 & 96.49 \\
\hline Neoadjuvant & 2 & 3.51 \\
\hline \multicolumn{3}{|l|}{ Response } \\
\hline CPR and micro only & 28 & 49.1 \\
\hline Partial & 2 & 3.5 \\
\hline Stable and progression & 15 & 26.3 \\
\hline Not assessable & 12 & 21.0 \\
\hline
\end{tabular}

ER: Estrogen receptor; PR: Progesterone receptor; CPR: complete pathologic response; micro only: microscopic residual disease only.

cal parameters. Survival analysis was calculated using the method of Kaplan-Meier. It was done using the SPSS Inc software (version 11). Relationship between qualitative parameters was determined using the Chi-Square and Student tests. Statistical significance was defined as $\mathrm{p}<0.05$.

\section{Results}

\section{Relationship between p53, Bcl-2 and ER, PR expression}

The expression rate of p53, Bcl-2, ER and PR was respec- 
Table 2. Histologic Subtypes

\begin{tabular}{lcc}
\hline Histologic subtypes & Number & \% \\
\hline Serous carcinoma & 24 & 42.1 \\
Endometrioid carcinoma & 23 & 40.3 \\
Malignant mixed epithelial tumour & 4 & 7 \\
Mucinous carcinoma & 3 & 5.3 \\
Undifferenciated carcinoma & 2 & 3.5 \\
Transitional cell carcinoma & 1 & 1.8 \\
\hline
\end{tabular}

tively $73.7 ; 47.4 ; 35.1$; and $33.3 \%$ (Fig. 1 and 2 ). In most cases, ER and PR were both detected or both absent. This association was statistically significant $(p=0,000)$ (Table 3 ). No significant association was found between p53 and Bcl-2 status (Table 4).

\section{Relationship between p53, Bcl-2 and ER and PR status and clinicopathological parameters}

The associations between protein expression and the clinicopathologic parameters are shown in Tables 5 and 6 .

A statistically significant positive correlation was observed between p53 expression and advanced disease (FIGO stage III/IV) $(p=0.026)$ and the presence of ascites at the time of staging laparotomy $\left(\mathrm{p}<10^{-4}\right)$. There was no significant correlation between $\mathrm{p} 53$ expression and age, size of re- sidual disease, histologic type and grade. PR expression was associated with an early FIGO stage $(p=0.045)$, a complete/ optimal primary surgery $(\mathrm{p}=0.013)$, a non serous histologic type $(\mathrm{p}=0.010)$ and a low tumor grade $(\mathrm{p}=0.036)$. No association was found between Bcl-2 and ER expression and the other clinicopathologic parameters studied.

At assessment on August 2008, 18 patients (31.5\%) were alive without evidence of disease, $9(15.7 \%)$ were alive with disease, $30(52.6 \%)$ had died of ovarian cancer.

In univariate analysis, the overall survival rate was significantly associated with the bcl-2 status $(\mathrm{p}=0.02)$, the FIGO stage $(\mathrm{p}=0.0135)$, the presence of ascites $(\mathrm{p}=$ $0.0165)$, peritoneal cytology status $(\mathrm{p}=0.0004)$ and the size of residual disease $(\mathrm{p}=0.0006)$. The results of analysis of the importance of clinicopathological parameters with regards to overall survival are presented in Figures 3-7.

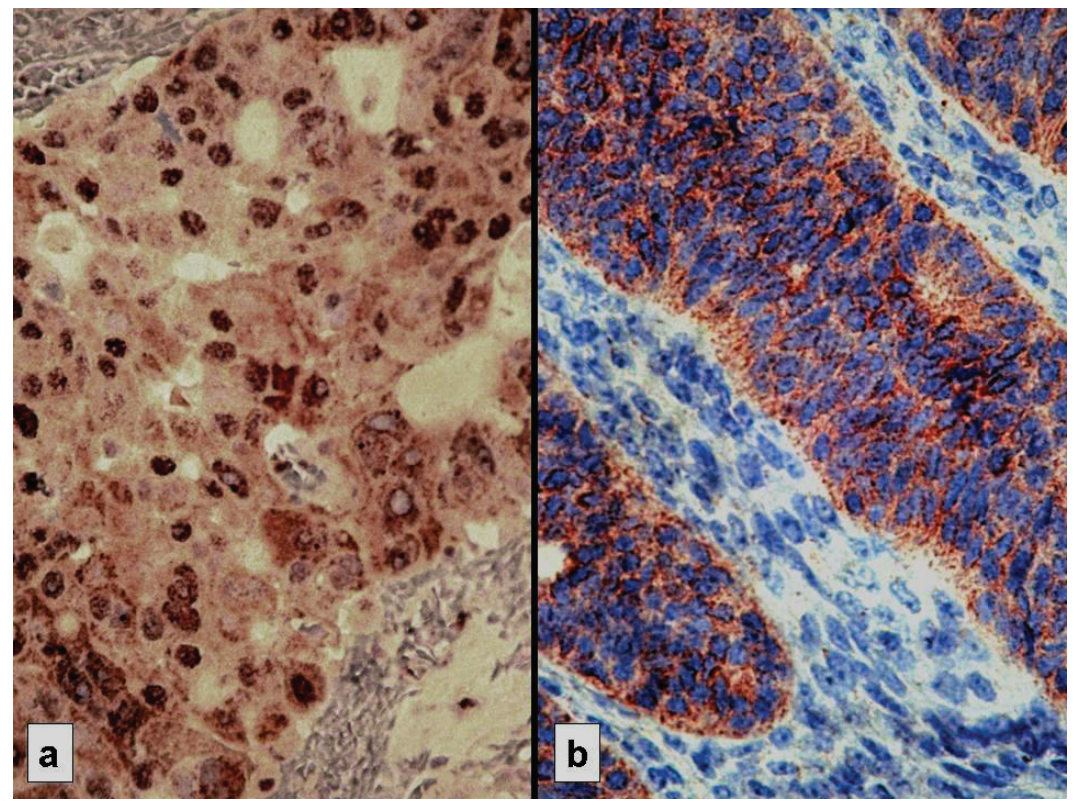

Figure 1. Strong immunostaining: nuclear for p53 (a) and cytoplasmic for Bcl-2 (b). 


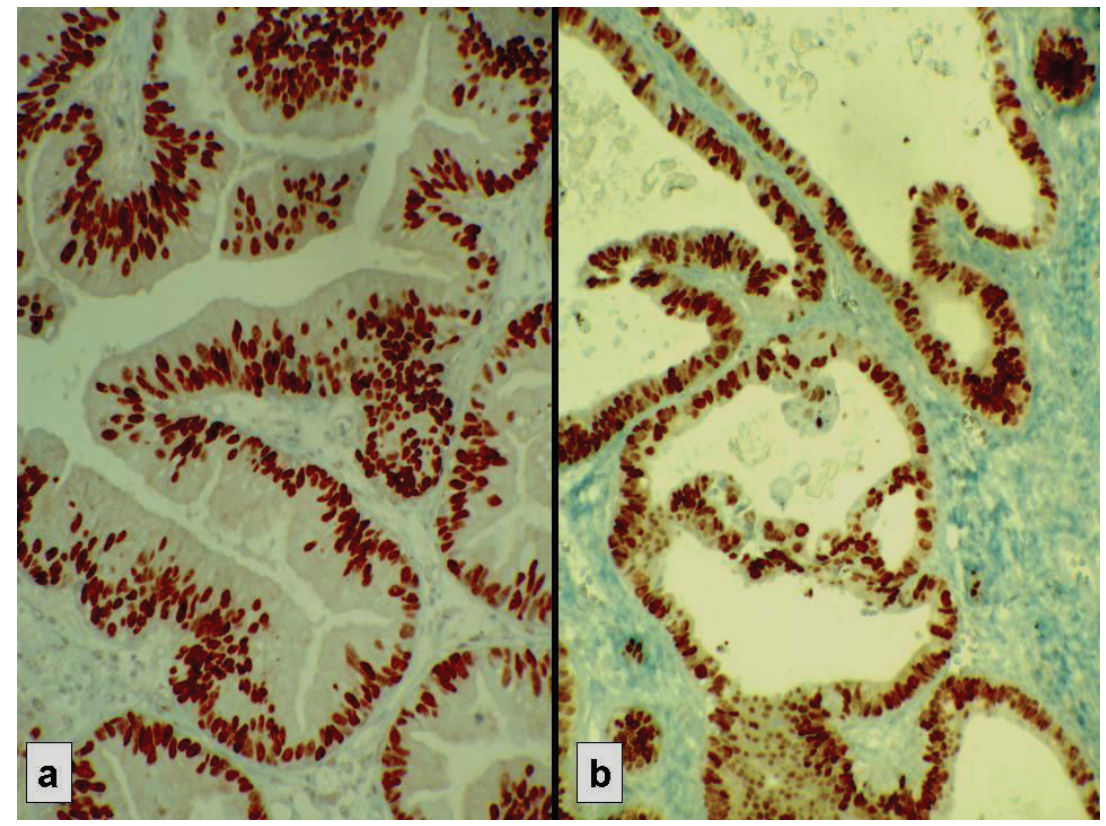

Figure 2. Strong nuclear immunostaining with hormonal receptors. (a) ER+, (b) PR+.

\section{Discussion}

The importance of p53 accumulation as a marker of adverse outcome in ovarian carcinoma has been demonstrated in several studies. Expression of p53 is associated with other unfavourable prognostic factors such as advanced FIGO stage, suboptimal cytoreduction, serous histologic subtype and increasing tumor grade. Nevertheless, its independent prognostic value remains controversial $[6,12]$. Some investigators have demonstrated that $\mathrm{p} 53$ mutation or overexpression is a significant prognostic factor [13-15]. Other studies have been unable to confirm such results [16-18]. In our series, the p53 status was associated with FIGO stage.

In contrast to $\mathrm{p} 53, \mathrm{Bcl}-2$ staining is most frequently as- sociated with favourable pathologic parameters: endometrioid subtype [19] and low tumor grade [20-22]. Regarding clinical parameters, only one study reported a significant correlation between Bcl-2 and optimal residual disease [23]. Consisting with the findings of several studies, Bcl-2 is associated with a prolonged survival thus with a good prognosis [20, 22-25]. However, some authors found a significant correlation between Bcl-2 status and primary resistance to chemotherapy [26-28]. In our study, Bcl-2 expression was not associated with any clinicopathological parameter. However, survival was significantly associated with bcl2 status $(\mathrm{p}=0.02)$. This result is in accordance with several reports $[20,22]$.

A significant inverse correlation between Bcl-2 expres-

Table 3. Correlation Between ER and PR Expression $(p=0.000)$

\begin{tabular}{lcccc}
\hline & & ER & Total \\
& & Negative & & \\
\hline \multirow{2}{*}{ PR } & & & & \\
& Negative & $33(86.8 \%)$ & $5(13.2 \%)$ & 38 \\
& Positive & $4(21.1 \%)$ & $15(78.9 \%)$ & 19 \\
Total & & 37 & 20 & 57 \\
\hline
\end{tabular}

ER: Estrogen receptor; PR: Progesterone receptor. 
Table 4. Correlation Between p53 and Bcl-2 Expression ( $p=0.949)$.

\begin{tabular}{|c|c|c|c|c|}
\hline & & \multicolumn{2}{|c|}{ p53 } & \multirow[t]{2}{*}{ Total } \\
\hline & & Negative & Positive & \\
\hline \multicolumn{5}{|l|}{ Bcl-2 } \\
\hline & Negative & $8(26.7 \%)$ & $22(73.3 \%)$ & 30 \\
\hline \multirow{2}{*}{ Total } & Positive & $7(25.9 \%)$ & $20(74.1 \%)$ & 27 \\
\hline & & 15 & 42 & 57 \\
\hline
\end{tabular}

Table 5. Correlation Between P53 and Bcl-2 Expression With Clinico-pathological Data

\begin{tabular}{|c|c|c|c|c|c|c|c|c|c|}
\hline & \multirow[b]{2}{*}{$\mathbf{N}$} & \multicolumn{4}{|c|}{ P53 Expression } & \multicolumn{4}{|c|}{ Bcl-2 Expression } \\
\hline & & $\%$ & $\mathbf{p}^{1}$ & Score \pm SD & $\mathbf{p}^{2}$ & $\%$ & $\mathbf{p}^{1}$ & Score \pm SD & $\mathbf{p}^{2}$ \\
\hline Age (years) & & & 0.611 & & 0.372 & & 0.153 & & 0.230 \\
\hline$\leq 55$ & 31 & 71 & & $3.23 \pm 3.48$ & & 38.7 & & $0.84 \pm 1.65$ & \\
\hline$>55$ & 26 & 76.9 & & $4.08 \pm 3.64$ & & 57.7 & & $1.42 \pm 1.98$ & \\
\hline FIGO Stage & & & 0.085 & & 0.026 & & 0.169 & & 0.893 \\
\hline I-II & 20 & 60 & & $2.20 \pm 3.25$ & & 35 & & $1.15 \pm 2.27$ & \\
\hline III-IV & 37 & 81.5 & & $4.38 \pm 3.50$ & & 54.1 & & $1.08 \pm 1.55$ & \\
\hline Residual disease & & & 0.611 & & 0.135 & & 0.716 & & 0.970 \\
\hline None/Optimal & 31 & 71 & & $2.97 \pm 3.33$ & & 45.2 & & $1.1 \pm 1.98$ & \\
\hline Sub-optimal & 26 & 76.9 & & $4.38 \pm 3.71$ & & 50 & & $1.12 \pm 1.63$ & \\
\hline Histologic type & & & 0.847 & & 0.320 & & 0.462 & & 0.271 \\
\hline Serous & 24 & 75 & & $4.17 \pm 3.66$ & & 41.7 & & $0.79 \pm 1.35$ & \\
\hline No Serous & 33 & 72.7 & & $3.21 \pm 3.46$ & & 51.5 & & $1.33 \pm 2.08$ & \\
\hline Histologic Grade & & & 0.061 & & 0.063 & & 0.629 & & 0.636 \\
\hline I-II & 34 & 64.7 & & $1.65 \pm 0.48$ & & 50 & & $1.50 \pm 0.50$ & \\
\hline III & 23 & 87 & & $1.87 \pm 0.34$ & & 43.5 & & $1.43 \pm 0.50$ & \\
\hline \multicolumn{10}{|l|}{ Ascites } \\
\hline$<100 \mathrm{ml}$ & 23 & 65.2 & 0.230 & $3.35 \pm 3.74$ & 0.646 & 39.1 & 0.306 & $0.83 \pm 1.58$ & 0.345 \\
\hline$>100 \mathrm{ml}$ & 34 & 79.2 & & $3.79 \pm 3.45$ & & 52.9 & & $1.29 \pm 1.96$ & \\
\hline Cytology & & & & & 0.452 & & 0.503 & & 0.892 \\
\hline negative & 28 & 71.4 & 0.700 & $3.25 \pm 3.58$ & & 42.9 & & $1.07 \pm 1.96$ & \\
\hline positive & 29 & 75.9 & & $3.97 \pm 3.54$ & & 51.7 & & $1.14 \pm 1.70$ & \\
\hline
\end{tabular}

$\mathrm{p}^{1}$ : Chi-Square test; $\mathrm{p}^{2}$ : Student test; \%: Positivity percentage; SD: standard deviation.

sion and p53 protein accumulation was found in several types of human cancers, especially malignant ovarian tumors [21].
Baekelandt et al [23] found in a series of 103 patients that Bcl-2 expression by itself was not an independent prognostic 
Table 6. Correlation Between ER and PR Status With Clinico-pathological Data

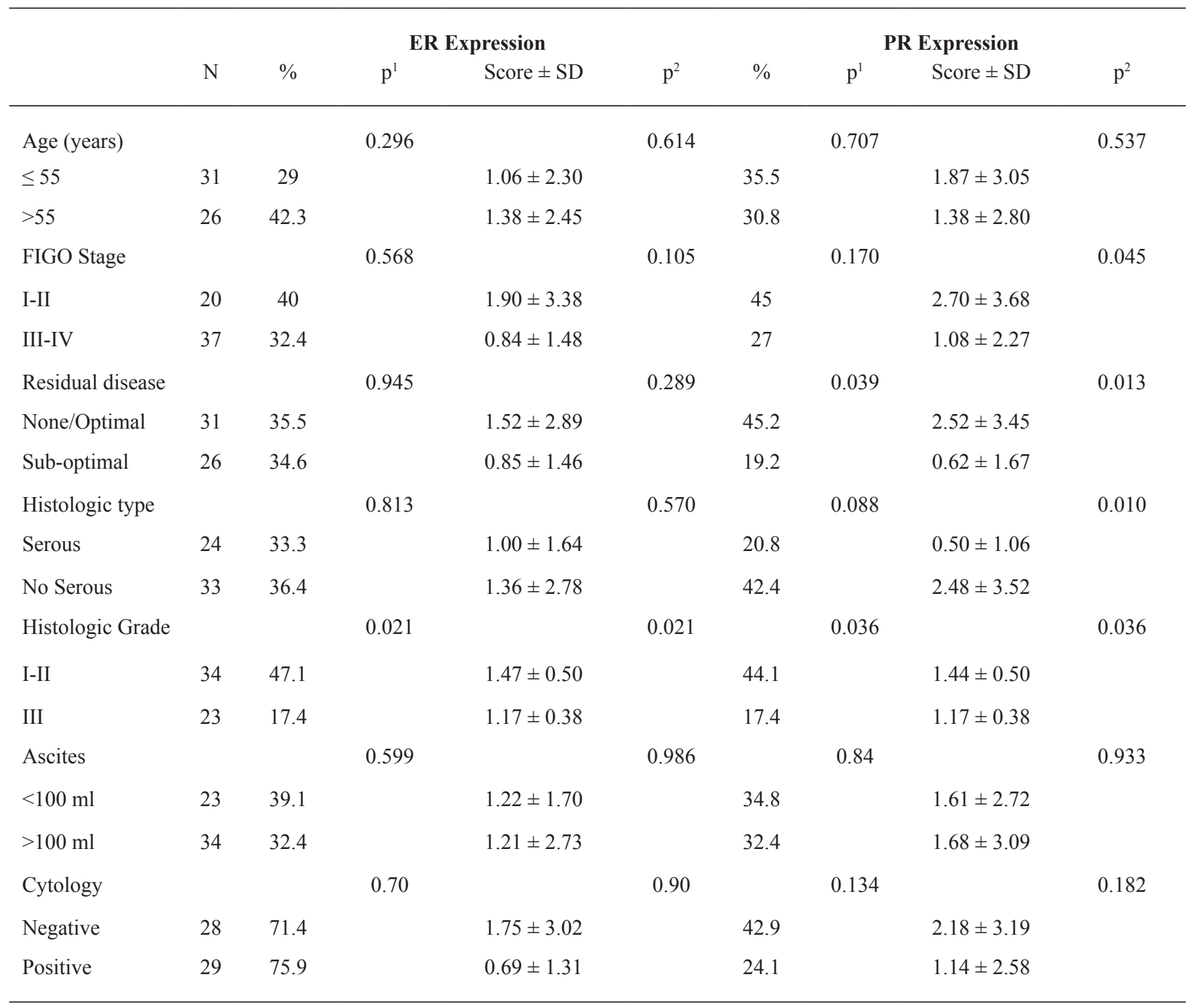

$p^{1}:$ Chi-Square test; $p^{2}$ : Student test; \%: positivity percentage; ER: Estrogen receptor; PR: Progesterone receptor; SD: standard deviation.

factor, but the combination of Bcl-2 and p53 staining was a stronger prognostic indicator than p53 expression alone.

Some trials researching in cancer therapies suggest that gene therapy with wild-type p53 [29, 30] or anti-Bcl-2 [31] could enhance response to chemotherapy. However, translation of these new insights to clinical usefulness remains the ultimate and perhaps the most difficult task of the future.

Data regarding the prognostic significance of ER and PR expression in ovarian carcinoma are limited and clinical value of determining steroid hormone receptors in this malignancy is still controversial $[9,32]$. This mainly accounts for different detection methods [9]. Today, immunohistochemistry is considered the method of choice because it allows an exact assignement of ER and PR expression to tissue components of interest [9]. Several studies demonstrated that the expression of PR is an independent indicator of favourable prognosis in ovarian carcinoma [9, 33-35] and significant inverse correlation was demonstrated for patient's age [9], FIGO stage [9, 34], residual tumor [9] and tumor grading $[9,36]$. In addition, PR is correlated with endometrioid histologic type [37]. In this study, we also found that PR expression was significantly correlated to early stage, optimal residual tumor, low grade and the group of non serous carcinomas including mainly endometrioid type. In accordance with our results, most reports found that ER status is not a prognostic factor in ovarian carcinoma and doesn't correlate with any clinicopathological parameter. Only few studies reported a significant expression of ER in advanced FIGO 


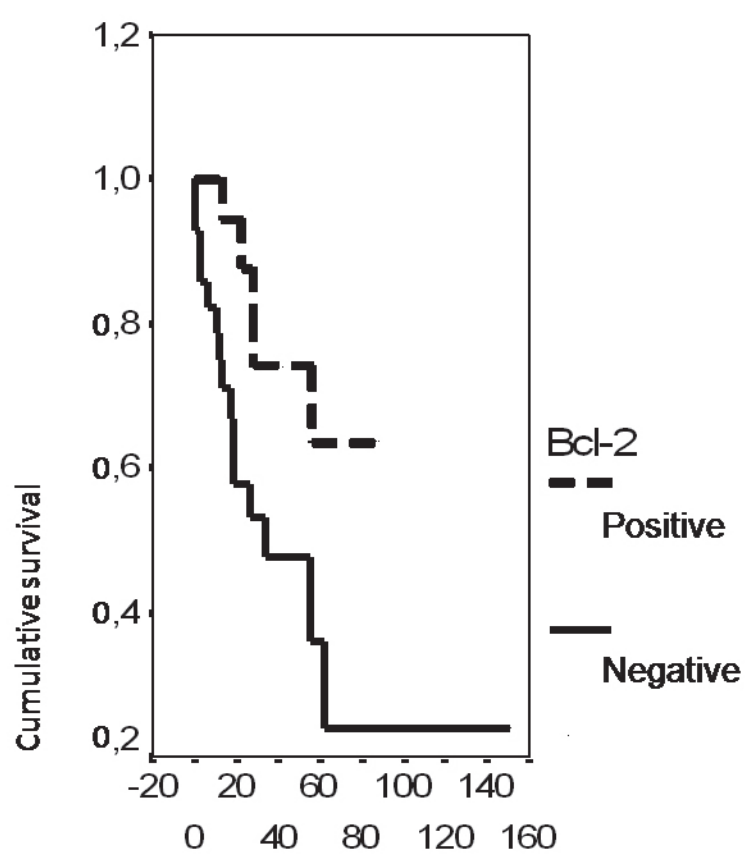

Figure 3. Cumulative survival probability in relation to $\mathrm{Bcl}-2$ status.

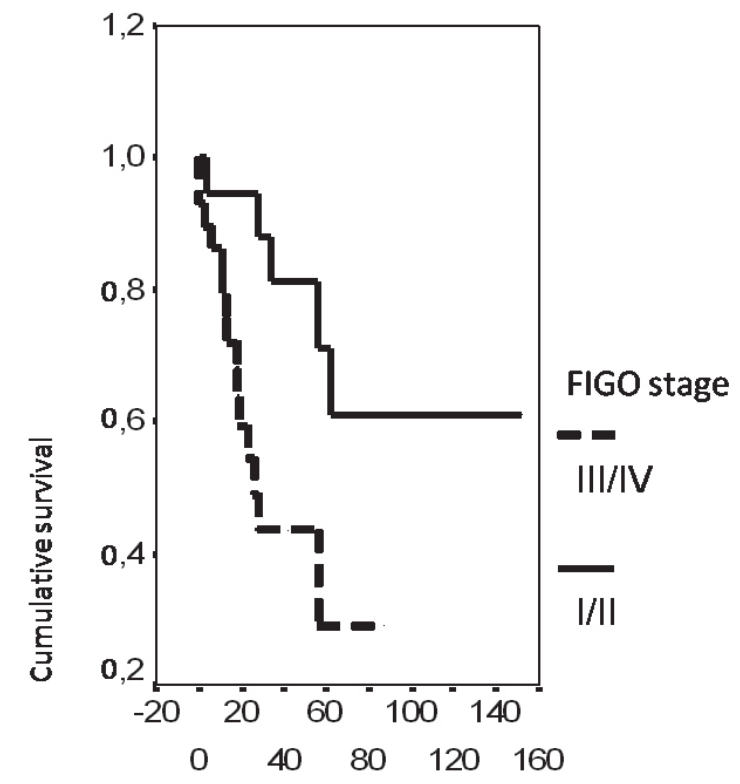

Figure 4. Cumulative survival probability in relation to FIGO stage.

stage [36]. Munstedt et al [9] demonstrated that the favourable course of PR positive ovarian carcinoma relates primarily to the subgroup ER-/PR+ expressing tumors. This tumor phenotype was associated with better prognosis compared to tumors with other steroid hormone receptors combination profiles. Although there is no single explanation for the ef-



Figure 5. Cumulative survival probability in relation to presence of ascites.

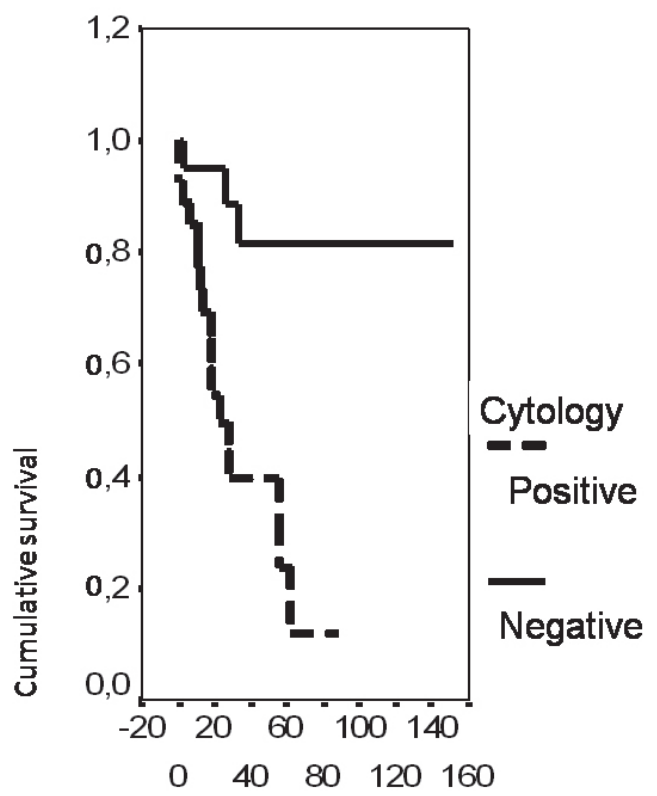

Figure 6. Cumulative survival probability in relation to peritoneal cytology.

fect of steroid hormone receptor expression on prognosis, two hypotheses have been proposed: 1) Estrogen-responsive cells efficiently repair DNA and avoid apoptosis, leading to clonal expansion and drug resistance [38]; 2) Progesterone promotes cell differentiation and apoptosis and stimulation of PR inhibits DNA synthesis and cell division [39]. 


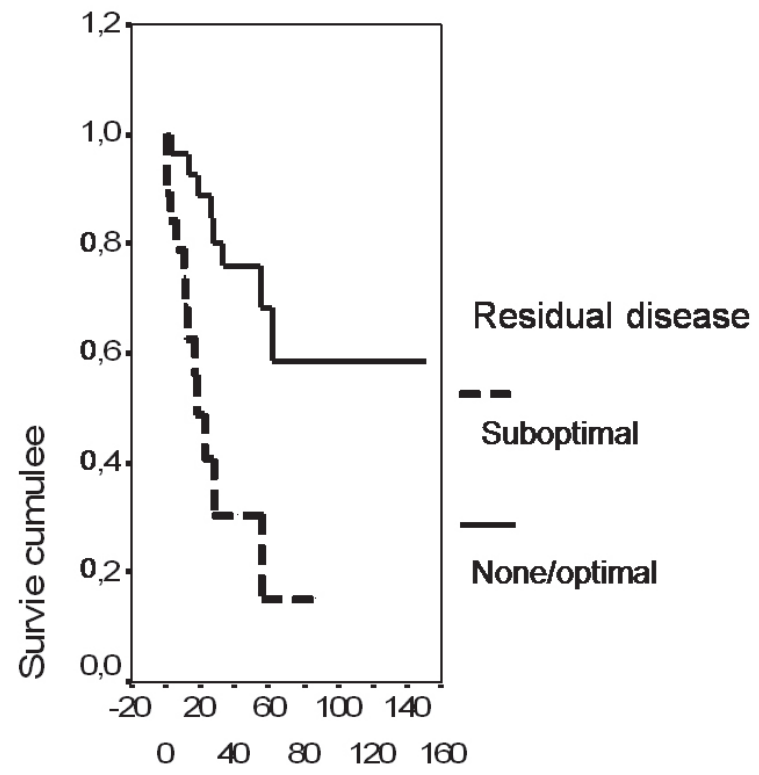

Figure 7. Cumulative survival probability in relation to residual disease.

Our results showed a significant correlation between ER and PR: they were both detected or both absent. We didn't study the ER/PR receptor combination because of the limited number of patients. Apart from prognosis, the predictive role of ER and PR expression with respect to hormonal therapy has not been confirmed [40]. In our study, survival was significantly worse with ascites, positive peritoneal cytology, late FIGO stage, residual lesions after cytoreductive surgery and negative bcl-2 status.

In conclusion, P53, Bcl-2 and hormone receptors status are potential prognostic factors in ovarian cancer. In this study about 57 Tunisian patients with ovarian carcinoma, biomarkers expression was evaluated by immunohistochemistry and was observed in 42 cases $(73.7 \%)$ for p53, 27 cases (47.4\%) for Bcl-2, 20 cases (35.1\%) for ER and 19 cases $(33.3 \%)$ for PR. Our results showed that p53 expression correlates with aggressiveness parameters such as advanced stage, ascites and positive cytology; whereas PR is associated with favourable prognostic parameters such as early stage, non serous histologic type and low tumor grade. Bcl2 status was significantly associated with better survival.

\section{Abbreviations}

ER: Estrogen receptor; PR: Progesteron receptor; WHO: World Health Organisation; FIGO: International Federation of Gynaecologists and Obstetrics.

\section{Acknowledgements}

We thank Mrs Mejda Mseddi who carried out the immunoperoxydase stains on the cases, Doctor Ahmed Sellami who contributed materials essential for the study and Professor Mohamed Issam Beyrouti, department chair who provided general support.

\section{Competing Interests}

The authors declare that they have no competing interests.

\section{Authors' Contributions}

LA designed the study, interpreted the results of p53, bcl2, ER and PR expression, and drafted the manuscript. SC reviewed the histopathology of ovarian carcinoma, graded all the cases histologically and helped to draft the manuscript. AK participated in the sequence alignement, supervision of the all slices and helped to draft the manuscript. HA reviewed all clinical data and helped to draft the manuscript. SM prepared the histological slides and helped the immunoperoxydase stains on the cases. MG participated in the design of the study and performed the statistical analysis. TSB concieved the study and participated in the design of the article and coordination and helped interpretation of the results of $\mathrm{p} 53$, bcl2, ER and PR expression.

\section{References}

1. Muir CS, Nectoux J: International patterns of cancer. In Cancer epidemiology and prevention. 2nd edition. Edited by Schottenfeld D, Fraumeni JF. New York: Oxford University Press; 1996:141-67.

2. Kristensen GB, Trope C. Epithelial ovarian carcinoma. Lancet 1997;349(9045):113-117.

3. Runnebaum IB, Stickeler E. Epidemiological and molecular aspects of ovarian cancer risk. J Cancer Res Clin Oncol 2001;127(2):73-79.

4. Hsairi M, Fakhfakh R, Ben Abdallah M, Jlidi R, Sellami A, Zheni S, Hmissa S, et al. [Assessment of cancer incidence in Tunisia 1993-1997]. Tunis Med 2002;80(2):5764.

5. Skirnisdottir I, Seidal T, Sorbe B. A new prognostic model comprising p53, EGFR, and tumor grade in early stage epithelial ovarian carcinoma and avoiding the problem of inaccurate surgical staging. Int J Gynecol Cancer 2004;14(2):259-270.

6. Eltabbakh GH, Belinson JL, Kennedy AW, Biscotti CV, Casey G, Tubbs RR, Blumenson LE. p53 overexpression is not an independent prognostic factor for 
patients with primary ovarian epithelial cancer. Cancer 1997;80(5):892-898.

7. Dogan E, Saygili U, Tuna B, Gol M, Gurel D, Acar B, Koyuncuoglu M. p53 and mdm2 as prognostic indicators in patients with epithelial ovarian cancer: a multivariate analysis. Gynecol Oncol 2005;97(1):46-52.

8. Sagarra RA, Andrade LA, Martinez EZ, Pinto GA, Syrjanen KJ, Derchain SF. P53 and Bcl-2 as prognostic predictors in epithelial ovarian cancer. Int J Gynecol Cancer 2002;12(6):720-727.

9. Munstedt K, Steen J, Knauf AG, Buch T, von Georgi $\mathrm{R}$, Franke FE. Steroid hormone receptors and long term survival in invasive ovarian cancer. Cancer 2000;89(8):1783-1791.

10. Shimizu Y, Kamoi S, Amada S, Hasumi K, Akiyama F, Silverberg SG. Toward the development of a universal grading system for ovarian epithelial carcinoma. I. Prognostic significance of histopathologic features-problems involved in the architectural grading system. Gynecol Oncol 1998;70(1):2-12.

11. Tavassoli FA, Devilee P: World Health Organization Classification of Tumors: Pathology and Genetics of tumors of the breast and female genital organs. Lyon IARC Press; 2003.

12. Marx D, Meden H, Ziemek T, Lenthe T, Kuhn W, Schauer A. Expression of the p53 tumour suppressor gene as a prognostic marker in platinum-treated patients with ovarian cancer. Eur J Cancer 1998;34(6):845-850.

13. Henriksen R, Strang P, Wilander E, Backstrom T, Tribukait B, Oberg K. p53 expression in epithelial ovarian neoplasms: relationship to clinical and pathological parameters, Ki-67 expression and flow cytometry. Gynecol Oncol 1994;53(3):301-306.

14. Levesque MA, Katsaros D, Yu H, Zola P, Sismondi P, Giardina G, Diamandis EP. Mutant p53 protein overexpression is associated with poor outcome in patients with well or moderately differentiated ovarian carcinoma. Cancer 1995;75(6):1327-1338.

15. Hartmann LC, Podratz KC, Keeney GL, Kamel NA, Edmonson JH, Grill JP, Su JQ, et al. Prognostic significance of p53 immunostaining in epithelial ovarian cancer. J Clin Oncol 1994;12(1):64-69.

16. Kohler MF, Kerns BJ, Humphrey PA, Marks JR, Bast RC, Jr., Berchuck A. Mutation and overexpression of p53 in early-stage epithelial ovarian cancer. Obstet Gynecol 1993;81(5 ( Pt 1)):643-650.

17. Allan LA, Campbell MK, Milner BJ, Eccles DM, Leonard RCF, Parkin DE: The significance of p53 mutation and overexpression in ovarian cancer prognosis. Int $\mathrm{J}$ Gynecol Cancer 1996;6:483-90.

18. Sheridan E, Silcocks P, Smith J, Hancock BW, Goyns MH. P53 mutation in a series of epithelial ovarian cancers from the U.K., and its prognostic significance. Eur J Cancer 1994;30A(11):1701-1704.
19. Kaern J, Aghmesheh M, Nesland JM, Danielsen HE, Sandstad B, Friedlander M, Trope C. Prognostic factors in ovarian carcinoma stage III patients. Can biomarkers improve the prediction of short- and long-term survivors? Int J Gynecol Cancer 2005;15(6):1014-1022.

20. Skirnisdottir I, Seidal T, Gerdin E, Sorbe B. The prognostic importance of $\mathrm{p} 53$, bcl-2, and bax in early stage epithelial ovarian carcinoma treated with adjuvant chemotherapy. Int J Gynecol Cancer 2002;12(3):265-276.

21. Chan WY, Cheung KK, Schorge JO, Huang LW, Welch WR, Bell DA, Berkowitz RS, et al. Bcl-2 and p53 protein expression, apoptosis, and p53 mutation in human epithelial ovarian cancers. Am J Pathol 2000;156(2):409417.

22. Diebold J, Baretton G, Felchner M, Meier W, Dopfer K, Schmidt M, Lohrs U. bcl-2 expression, p53 accumulation, and apoptosis in ovarian carcinomas. Am J Clin Pathol 1996;105(3):341-349.

23. Baekelandt M, Kristensen GB, Nesland JM, Trope CG, Holm R. Clinical significance of apoptosis-related factors p53, Mdm2, and Bcl-2 in advanced ovarian cancer. J Clin Oncol 1999;17(7):2061.

24. Henriksen R, Wilander E, Oberg K. Expression and prognostic significance of Bcl-2 in ovarian tumours. $\mathrm{Br}$ J Cancer 1995;72(5):1324-1329.

25. Herod JJ, Eliopoulos AG, Warwick J, Niedobitek G, Young LS, Kerr DJ. The prognostic significance of Bcl2 and p53 expression in ovarian carcinoma. Cancer Res 1996;56(9):2178-2184.

26. Kassim SK, Ali HS, Sallam MM, Fayed ST, Seada LS, abd-Elkawy E, Seada MA, et al. Increased bcl-2 expression is associated with primary resistance to chemotherapy in human epithelial ovarian cancer. Clin Biochem 1999;32(5):333-338.

27. Mano Y, Kikuchi Y, Yamamoto K, Kita T, Hirata J, Tode $\mathrm{T}$, Ishii K, et al. Bcl-2 as a predictor of chemosensitivity and prognosis in primary epithelial ovarian cancer. Eur J Cancer 1999;35(8):1214-1219.

28. Yu L, Wang Z. Difference in expression of Bcl-2 and Bcl-xl genes in cisplatin-sensitive and cisplatin-resistant human in ovarian cancer cell lines. J Huazhong Univ Sci Technolog Med Sci 2004;24(2):151-153.

29. Gurnani M, Lipari P, Dell J, Shi B, Nielsen LL. Adenovirus-mediated p53 gene therapy has greater efficacy when combined with chemotherapy against human head and neck, ovarian, prostate, and breast cancer. Cancer Chemother Pharmacol 1999;44(2):143-151.

30. Buller RE, Runnebaum IB, Karlan BY, Horowitz JA, Shahin M, Buekers T, Petrauskas S, et al. A phase I/II trial of $\mathrm{rAd} / \mathrm{p} 53$ (SCH 58500) gene replacement in recurrent ovarian cancer. Cancer Gene Ther 2002;9(7):553566.

31. Barvaux VA, Lorigan P, Ranson M, Gillum AM, McElhinney RS, McMurry TB, Margison GP. Sensitization 
of a human ovarian cancer cell line to temozolomide by simultaneous attenuation of the Bcl-2 antiapoptotic protein and DNA repair by O6-alkylguanine-DNA alkyltransferase. Mol Cancer Ther 2004;3(10):1215-1220.

32. Tomsova M, Melichar B. Contribution of immunohistochemistry in prognostic assessment of epithelial ovarian carcinoma --review of the literature I. Acta Medica (Hradec Kralove) 2006;49(3):161-165.

33. Akahira J, Inoue T, Suzuki T, Ito K, Konno R, Sato $\mathrm{S}$, Moriya $\mathrm{T}$, et al. Progesterone receptor isoforms $\mathrm{A}$ and $\mathrm{B}$ in human epithelial ovarian carcinoma: immunohistochemical and RT-PCR studies. Br J Cancer 2000;83(11):1488-1494.

34. Harding M, Cowan S, Hole D, Cassidy L, Kitchener H, Davis J, Leake R. Estrogen and progesterone receptors in ovarian cancer. Cancer 1990;65(3):486-491.

35. Hempling RE, Piver MS, Eltabbakh GH, Recio FO. Progesterone receptor status is a significant prognostic variable of progression-free survival in advanced epithelial ovarian cancer. Am J Clin Oncol 1998;21(5):447-451.
36. Hogdall EV, Christensen L, Hogdall CK, Blaakaer J, Gayther S, Jacobs IJ, Christensen IJ, et al. Prognostic value of estrogen receptor and progesterone receptor tumor expression in Danish ovarian cancer patients: from the 'MALOVA' ovarian cancer study. Oncol Rep 2007;18(5):1051-1059.

37. Lee P, Rosen DG, Zhu C, Silva EG, Liu J. Expression of progesterone receptor is a favorable prognostic marker in ovarian cancer. Gynecol Oncol 2005;96(3):671-677.

38. Murdoch WJ, Van Kirk EA. Oestradiol inhibits spontaneous and cisplatin-induced apoptosis in epithelial ovarian cancer cells: relationship to DNA repair capacity. Apoptosis 1997;2(5):478-484.

39. Murdoch WJ. Perturbation of sheep ovarian surface epithelial cells by ovulation: evidence for roles of progesterone and poly(ADP-ribose) polymerase in the restoration of DNA integrity. J Endocrinol 1998;156(3):503-508.

40. Zheng H, Kavanagh JJ, Hu W, Liao Q, Fu S. Hormonal therapy in ovarian cancer. Int J Gynecol Cancer 2007;17(2):325-338. 